\title{
Assessment of the Spatial Invasion Risk of Intentionally Introduced Alien Plant Species (IIAPS) under Environmental Change in South Korea
}

\author{
Pradeep Adhikari ${ }^{1,+}$ D, Yong-Ho Lee ${ }^{1,2,+}$, Yong-Soon Park ${ }^{3, *}$ and Sun-Hee Hong ${ }^{4, *}$ (D) \\ 1 Institute of Ecological Phytochemistry, Hankyong National University, Anseong 17579, Korea; \\ pdp2042@gmail.com (P.A.); yongho@korea.ac.kr (Y.-H.L.) \\ 2 OJeong Resilience Institute, Korea University, Seoul 02841, Korea \\ 3 Biotechnology Research Institute, College of Natural Sciences, Chungbuk National University, \\ Cheongju 28644, Korea \\ 4 School of Plant Science and Landscape Architecture, College of Agriculture and Life Sciences, \\ Hankyong National University, Anseong 17579, Korea \\ * Correspondence: yspark2005@cbnu.ac.kr (Y.-S.P.); shhong@hknu.ac.kr (S.-H.H.) \\ + These authors contributed equally to this work.
}

Citation: Adhikari, P.; Lee, Y.-H.; Park, Y.-S.; Hong, S.-H. Assessment of the Spatial Invasion Risk of Intentionally Introduced Alien Plant Species (IIAPS) under Environmental Change in South Korea. Biology 2021, 10, 1169. https://doi.org/10.3390/ biology10111169

Academic Editor: Philip J. Seddon

Received: 13 September 2021

Accepted: 9 November 2021

Published: 12 November 2021

Publisher's Note: MDPI stays neutral with regard to jurisdictional claims in published maps and institutional affiliations.

Copyright: (c) 2021 by the authors. Licensee MDPI, Basel, Switzerland. This article is an open access article distributed under the terms and conditions of the Creative Commons Attribution (CC BY) license (https:// creativecommons.org/licenses/by/ $4.0 /)$.
Simple Summary: The spatial distribution and invasion risk of 10 intentionally introduced alien plant species (IIAPS) in South Korea were predicted from a species distribution model via a maximum entropy modeling approach. According to the model predictions, future environmental changes are likely to enlarge the range of the spatial distribution of all studied IIAPS in South Korea except Medicago sativa. We classified the IIAPS into three categories based on their spatial distribution and potential to spread; this revealed that four species (Coreopsis lanceolate, Eragrostis curvula, Ageratina altissima, and Lolium perenne) have the highest potential for invasion. Moreover, we classified invasion risk into three categories, low, moderate, and high, and estimated the area in each category. We found that, under current conditions, much of the country is at low risk (47.96\%) of invasion, but by $2050>54 \%$ of the country's total area will be at high risk of invasion by IIAPS. Serious invasion of IIAPS into cropland, pastures, and forests results in the loss of native biodiversity and damage to the national economy. Therefore, immediate action is required to control and manage IIAPS in South Korea.

Abstract: Predicting the regions at risk of invasion from IIAPS is an integral horizon-scanning activity that plays a crucial role in preventing, controlling, and eradicating invasive species. Here, we quantify the spatial distribution area and invasion risk of IIAPS using a species distribution model under different levels of environmental change in South Korea. From the model predictions, the current average spatial extent of the 10 IIAPS is $33,948 \mathrm{~km}^{2}$, and the individual spatial extents are estimated to change by $-7 \%$ to $150 \%$ by 2050 and by $-9 \%$ to $156 \%$ by 2070 . The spatial invasion risk assessment shows that, currently, moderate-to-high invasion risk is limited to coastal areas and densely populated metropolitan cities (e.g., Seoul, Busan, and Gwangju), but that the area with this level of risk is expected to spread toward the central and northern regions of the country in the future, covering $86.21 \%$ of the total area of the country by 2070 . These results demonstrate that the risk of invasion by IIAPS is estimated to enlarge across the whole country under future environmental changes. The modeling system provided in this study may contribute to the initial control and strategic management of IIAPS to maintain the dynamic ecosystems of South Korea.

Keywords: climate change; intentionally introduced alien plants; invasion risk; land cover change; province; spatial distribution 


\section{Introduction}

Invasion risk is the likelihood that non-native species will be introduced to and become established within a novel ecosystem, either intentionally or inadvertently, thereby threatening native biodiversity, ecosystem services, and human well-being [1-3]. Some alien plant species are intentionally introduced to non-native regions because of their importance in agriculture, horticulture, pastoral productivity, or land rehabilitation $[4,5]$. After the successful establishment and proliferation of introduced species, many become dominant in diverse areas with subsequent invasion of non-target ecosystems along various pathways [6], ultimately resulting in unexpected conservation challenges [5].

Usually, the non-native plant species have some specific functional traits $[7,8]$ that support the introduction, naturalization, and invasion of new areas [9]. They are often ruderal, growing along transportation corridors, irrigation canals, the seashore, and riversides as noxious weeds [10]. Increasing the number of non-native species in some regions amplifies the magnitude of invasion risk [11]. Uncontrolled expansion of such species alters the pools and fluxes of an ecosystem and can cause grievous reductions in crop yields, resulting in substantial economic losses [2,12-15].

Global climate change may exacerbate the risk of invasion of alien plant species through ecosystem destruction and increased competition within native ecological systems because of elevated carbon dioxide $\left(\mathrm{CO}_{2}\right)[16,17]$. In addition, climate change encourages rapid range shift and changes the life cycle, life-history traits, and population dynamics of invasive plants [18-21]. In the last century, the global temperature increased by $0.78{ }^{\circ} \mathrm{C}$ and is projected to increase by $2.6^{\circ} \mathrm{C}$ to $4.8^{\circ} \mathrm{C}$ by 2100 [22]. In addition to climate change, changes in land cover are important to the introduction, establishment, and spread of alien plant species, including invasive weeds [23]. Land cover changes may provide a suitable habitat for particular plants to invade an area, inhibiting others and acting as a dispersal corridor [24-26]. Land cover changes such as forest clearing for urbanization, agriculture, or pastoral purposes facilitate biological invasion [26].

Alien plant species were first introduced into South Korea prior to 1949 for agricultural or horticultural reasons, pastoral land management, or erosion control [27]. Eighty-one taxa of alien plants introduced into South Korea have successfully naturalized and seriously threatened native plant communities growing in fields, orchards, forests, and pastures [28,29]. Jeju province has the highest number of alien plant species in South Korea $[27,28]$. It has been reported that invasive and alien plant species cause approximately 19.6 million USD of economic damage per year in South Korea, and the government invests about 4.3 million USD per year in the management of invasive weeds, including control and eradication [15]. Moreover, South Korea's land cover has altered rapidly due to the development of the modern transportation system, industrialization, and coastal land reclamation [30,31]. Under these circumstances, the issue of how to monitor and manage intentionally introduced alien plant species (IIAPS) in South Korea should be an important subject of discussion.

A maximum entropy (MaxEnt) modeling approach is normally required to assess the spatial distribution of IIAPS and estimate their potential invasion risk under climate and land cover changes [32-35]. Although MaxEnt is widely regarded as a suitable tool, almost no MaxEnt studies on the spatial distribution of IIAPS have been reported in South Korea: we designed this study to bridge this gap. The main objectives of this study were (1) to analyze the impacts of bioclimatic, land cover change, road transportation, and water proximity variables on the occurrence probability of IIAPS; (2) to evaluate the spatial distribution of IIAPS with the MaxEnt algorithm and estimate the risk of spatial invasion under current and future environmental changes in South Korea; and (3) to classify the IIAPS into groups according to their spatial distribution and invasion potential, to prioritize control and management strategies. We estimated three categories of spatial invasion risklow, moderate, and high-across the country and existing provinces. Our study shows that future environmental changes increased both the extent and the intensity of spatial invasion of IIAPS in South Korea and that the studied species could disrupt ecosystems 
on a large scale in the future. The modeling system used sheds light on the potential spatial distribution of invasive weeds and IIAPS in the near future and the associated risk assessments.

\section{Materials and Methods}

\subsection{Study Areas}

South Korea is located in East Asia and constitutes the southern portion of the Korean Peninsula. South Korea has a total landmass of $98,477 \mathrm{~km}^{2}$, excluding the demilitarized zone along the boundary with North Korea (Figure 1). It is surrounded by three seas along the east (East Sea), west (Yellow Sea), and south (East China Sea) and has a coastline approximately $2413 \mathrm{~km}$ in length [36]. The country is mostly mountainous (approximately $70 \%$ of the country) in the east and north, with lowlands and flat plains occupying the remaining $30 \%$ in the west and south [36].

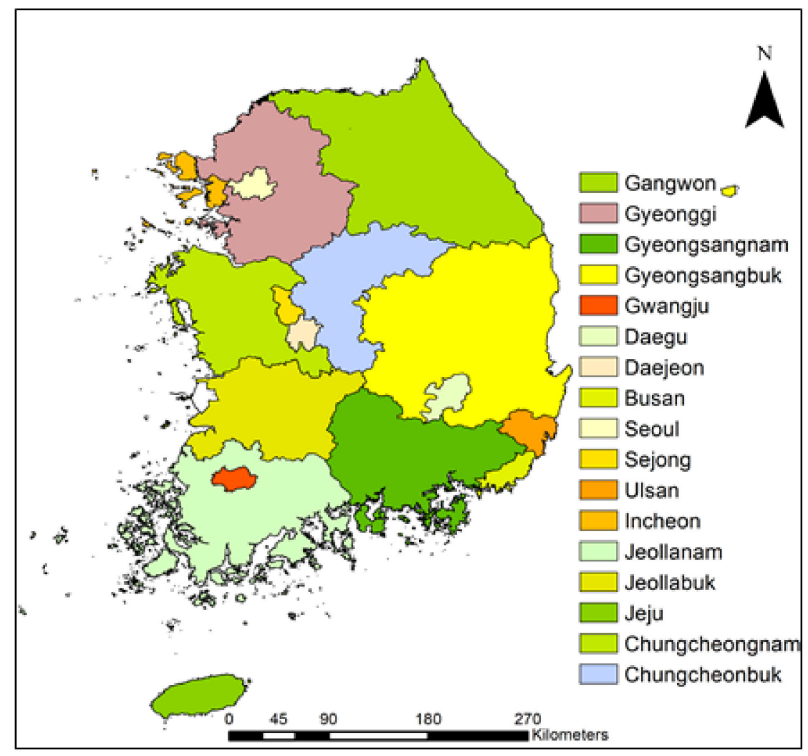

Figure 1. Administrative divisions (major cities and provinces) and geographical boundaries of South Korea.

The climate of South Korea can be mainly divided into cold-temperate, temperate, and warm-temperate regions, located in the northern region plus high mountains, the central region, and the southern region, respectively, with four distinct seasons of spring, summer, autumn, and winter [37]. The winter is long, dry, and cold, while the summer is short, humid, and hot. The autumn and spring are sunny and usually dry and pleasant. The average winter temperatures range between $-6{ }^{\circ} \mathrm{C}$ and $3{ }^{\circ} \mathrm{C}$, and the average summer temperatures range between $23{ }^{\circ} \mathrm{C}$ and $26{ }^{\circ} \mathrm{C}$. Similarly, annual precipitation records 1000 to $1800 \mathrm{~mm}$ [38]. The southern coast, adjacent mountains, and Jeju Island have the largest amount of rainfall, recording over $1500 \mathrm{~mm}$ in a year [38].

The vegetation of South Korea is primarily divided into alpine, subalpine, coniferous, deciduous broadleaf, and temperate broadleaf. The overall biodiversity has been reported to comprise 41,483 species, of which 2177 are endemic [36,37]. Of the total species, 5308 are vascular plants, 22,612 are invertebrates, and 1899 are vertebrates [36]. The current study focused on 250 districts in 17 administration divisions (provinces and metropolitan cities) in South Korea (Figure 1).

\subsection{Occurrence of Intentionally Introduced Alien Plant Species}

Ten alien plant species (Table 1 and Figure 2) introduced intentionally in South Korea were selected based on their rapid range expansion, their degree of invasion into natural ecosystems $[27,28]$, and the availability of minimum species occurrence records. 
Species presence points for such species were noted through field surveys performed from March 2014 to November 2020, and additional presence points were collected from the literature [28,39]. We used Garmin GPSmap 64SX (Garmin, Ltd., Seoul, Korea) to record the occurrence and location of species to measure the dispersal of invasive weeds. The species presence survey, plot design, and survey techniques were all conducted according to the National Institute of Ecology [28]. Multiple species presence points in the same grid at a spatial resolution of $1 \mathrm{~km}^{2}$ were erased and then retained as a single unique point per grid by applying the spatially rarefy occurrence data tool using the SDM toolbox 2.4 in the Arc GIS [40]. This avoids incorrect inflation of model outputs and overfitting because of the spatial autocorrelation [41]. The total species occurrence points for the 10 IIAPS were reduced from 7389 to 4671 after spatial filtering, and those points were employed in the MaxEnt modeling. The species occurrence for each IIAPS is presented in the Supplementary Figure S1a-j.

Table 1. List of intentionally introduced alien plant species (IIAPS) used in the species distribution model.

\begin{tabular}{|c|c|c|c|c|c|c|c|}
\hline $\begin{array}{l}\text { IAPAS } \\
\text { Group }^{\mathrm{a}}\end{array}$ & ID No. & Scientific Name & Common Name & Native Range & $\begin{array}{c}\text { Mode of } \\
\text { Introduction }\end{array}$ & $\begin{array}{l}\text { Introduction } \\
\text { Period }\end{array}$ & $\begin{array}{c}\text { Degree of } \\
\text { Naturalization }\end{array}$ \\
\hline Group 1 & I 223 & Medicago sativa & Alfalfa & Mediterranean & $\begin{array}{c}\text { Intentional } \\
\text { (Pasture) }\end{array}$ & Before 1949 & III \\
\hline \multirow{5}{*}{ Group 2} & I072 & Amorpha fruticosa & Bastard indigo bush & North America & $\begin{array}{c}\text { Intentional } \\
\text { (Erosion control) }\end{array}$ & Before 1949 & $\mathrm{~V}$ \\
\hline & $\mathrm{I} 138$ & Dactylis glomerata & Orchard grass & North Africa & $\begin{array}{l}\text { Intentional } \\
\text { (Pasture) }\end{array}$ & Before 1949 & $\mathrm{~V}$ \\
\hline & I165 & Festuca arundinacea & Tall fescue & North Africa & $\begin{array}{l}\text { Intentional } \\
\text { (Pasture) }\end{array}$ & Before 1970 & $\mathrm{~V}$ \\
\hline & I176 & Helianthus tuberosus & Jerusalem artichoke & North America & $\begin{array}{l}\text { Intentional } \\
\text { (medicinal) }\end{array}$ & Before 1911 & $\mathrm{~V}$ \\
\hline & $\mathrm{I} 258$ & Poa pratensis & Kentucky bluegrass & Temperate zone & $\begin{array}{c}\text { Intentional } \\
\text { (Erosion control) }\end{array}$ & Before 1949 & IV \\
\hline \multirow{4}{*}{ Group 3} & I129 & Coreopsis lanceolata & Lance leaf coreopsis & North America & $\begin{array}{c}\text { Intentional } \\
\text { (Erosion control) }\end{array}$ & Before 1963 & $\mathrm{~V}$ \\
\hline & $\mathrm{I} 150$ & Eragrostis curvula & African love grass & North Africa & $\begin{array}{c}\text { Intentional } \\
\text { (Erosion control) }\end{array}$ & Before 1990 & IV \\
\hline & I157 & Ageratina altissima & White snakeroot & North America & $\begin{array}{c}\text { Intentional } \\
\text { (Gardening) }\end{array}$ & Before 1990 & IV \\
\hline & I210 & Lolium perenne & Ryegrass & North Africa & $\begin{array}{c}\text { Intentional } \\
\text { (Pasture) }\end{array}$ & Before 1970 & IV \\
\hline
\end{tabular}

a Division into group 1, group 2, or group 3 was based on the principal component analysis of the spatial distribution of intentionally introduced alien plant species (IIAPS) shown in Figure 3. The Roman numerals I to IV in the last column indicate the degree of naturalization of the IIAPS. I, rarely; II, low density and distributed in a small area; III, low density but distributed widely; IV, high density and distributed locally; V, high density and distributed widely.

\subsection{Environmental Variables}

We collected raw data for bioclimatic variables [42,43], including monthly minimum and maximum temperatures and monthly precipitation, from the Korea Meteorological Administration (KMA). We estimated climate change scenarios according to the representative concentration pathways (RCPs) of 4.5 and 8.5 in 2050 and 2070, respectively, which suggest that the projected global mean surface temperature will increase by $1.4-1.8^{\circ} \mathrm{C}$ and 2.0-3. ${ }^{\circ} \mathrm{C}$, respectively, compared with current levels [22].

The physical properties of the earth's surface, atmosphere, cryosphere, and ocean are all considered in global circulation models (GCMs). These models keep track of the basic systems that adapt to climate change (e.g., surface albedo changes, aerosols, solar irradiance, and concentrations of greenhouse gases) [44]. The HadGEM3-RA is a regional atmospheric model developed by the Meteorological Office Hadley Center (www.metoffice.gov.uk, accessed on 29 July 2021) and utilized by the KMA for dynamical downscaling to seasonal and continental scales. It was used together with the Coordinated 
Regional Climate Downscaling Experiment [45] to prepare the national climate change scenario for South Korea. The HadGEM3-RA reproduces small-scale features, such as the coastline and intricate topography of the Korean Peninsula, more realistically than other GCMs because of their high resolution [45,46]. Therefore, we used the HadGEM3-RA to prepare the climate change scenarios (RCP 4.5 and RCP 8.5) using the "Dismo Package" in R [47], similar to previous studies performed in South Korea [48-53].

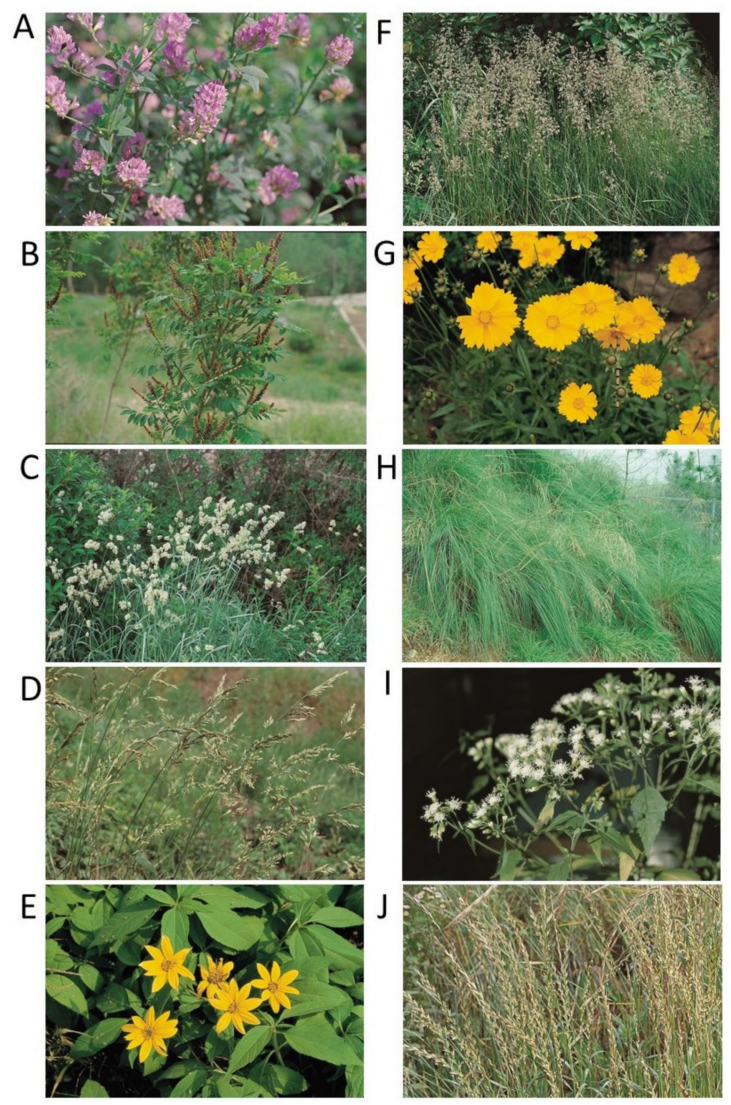

Figure 2. Photographs of ten introduced alien plant species in South Korea. (A) Medicago sativa; (B) Amorpha fruticose; (C) Dactylis glomerate; (D) Festuca arundinacea; (E) Helianthus tuberosus; (F) Poa pratensis; (G) Coreopsis lanceolate; (H) Eragrostis curvula; (I) Ageratina altissima; and (J) Lolium perenne.

The current climate was determined from average climatic data recorded from 1950 to 2010, and the future climate temperatures for 2050 and 2070 were estimated from predictions for 2046 to 2055 and 2066 to 2075, respectively. Each climatic dataset had a spatial resolution of 30 arc seconds $\left(\sim 1 \mathrm{~km}^{2}\right.$ at the equator), with the same spatial extent and geographical coordination system (WGS 1984 datum).

In addition to the bioclimatic variables, we used three other environmental variables, including seven categories of land cover (e.g., agricultural land, grassland, forest, urban area, water, wetland, and barren land), distance from roads (d-road), and distance from water (d-water) in the modeling of invasive weeds. The land cover change scenarios were downloaded from the Korea Adaptation Center for Climate Change (https: / / kaccc.kei.re.kr, accessed on 11 August 2021).

Roads and highways serve as ideal habitats and corridors for IIAPS to spread and proliferate. IIAPS that have become established along roads can serve as a source of invasion into the adjacent forests, grassland, and agricultural land [54]. South Korea is rich in water resources, with thousands of streams, rivers, and lakes across the country. IIAPS grow in the disturbed areas close to these water sources. Streams and rivers thus have an important role in IIAPS seed dispersal. Therefore, we prepared d-road and 
d-water in ArcGIS 10.3 (Esri, Redlands, CA, USA) using the Euclidian distance function with a resolution of $1 \mathrm{~km}^{2}$. To eliminate autocorrelation $\left(\mathrm{r}^{2}>0.75, p=0.05\right)$ among the environmental variables, we used Spearman's correlation on pairs with the Proc Corr function of SAS 9.4 (SAS Institute, Inc., Cary, NC, USA). We picked nine important variables with low correlation and high predictive performance, as in Shin et al. [50] and Hong et al. [55] (Table S1).

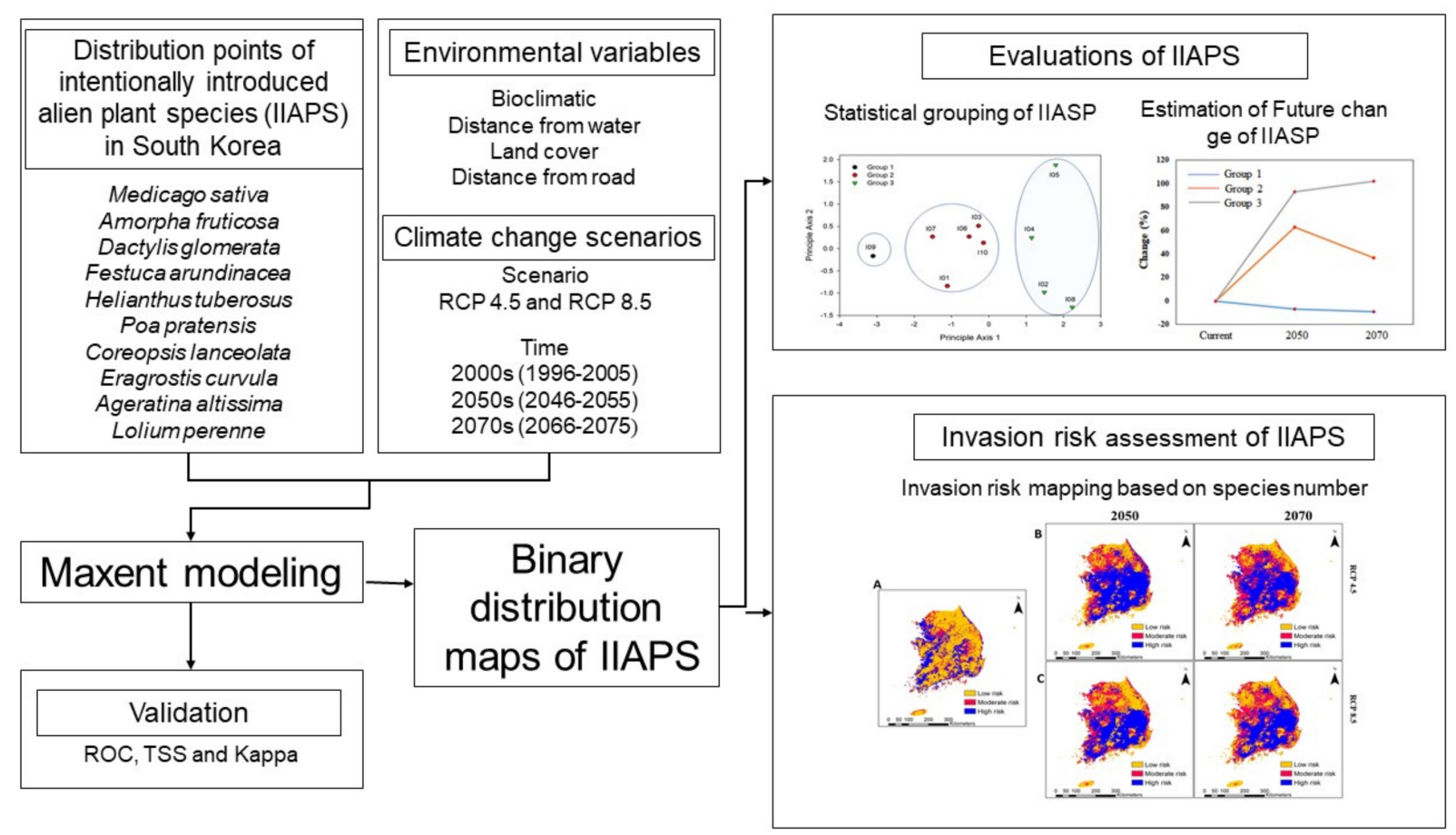

Figure 3. Flow—chart of the development and building blocks of the MaxEnt model and its practical application in estimating the invasion risk of intentionally introduced alien plant species in South Korea.

\subsection{Species Distribution Modeling}

Species distribution modeling (SDM) is an approach for estimating a species' distribution throughout global space and time by applying a correlation between the species' geographic occurrence and its surrounding environment [56]. The SDM approach has been used in various sectors of ecology over the last decade to predict species' potential habitat under future climate changes [57], including IIAPS [49,58,59]. Various SDM tools such as machine learning, statistical regression, and spatial interpolation are currently used to model species distribution [56]. Among these tools, MaxEnt is a machine-learning modeling technique for predicting suitable habitats. It is used worldwide because it exhibits a high predictive performance from small sets of species presence data and environmental variables [60]. Thus, we performed MaxEnt modeling using "Biomod2" Package v.3.5.1, selecting a single model MAXENT.Phillips.2 [61] for the prediction of spatial distributions of ten selected IIAPS in South Korea. In this study, $75 \%$ of the species occurrence data were used for model calibration, and the remaining $25 \%$ were used for model validation. The MaxEnt model requires background points (e.g., pseudo-absences): we used ArcGIS 10.3 to determine 15,052 background points from the study area, as suggested by Barbet-Massin et al. [62]. The other options in the MaxEnt model were set to the default values, and the model was run 100 times.

\subsection{Model Evaluation and Validation}

To investigate the goodness-of-fit of the model used in this study, we examined three evaluating parameters: the area under the curve (AUC) values of the receiver operating characteristic (ROC) curves [63], the true skill statistic (TSS) [64], and the kappa statistic. 
The AUC, TSS, and kappa values were calculated from the test data points. The AUC is a threshold-independent technique for distinguishing presence from an absence that is used to test model outcomes. The AUC value ranges from 0 to 1 and evaluates the performance of a model [65].

The AUC value is independent of the data size (prevalence); however, its use can be criticized because it weights commission and omission errors equally and may avoid true predictions [66]. In particular, expanding the geographical range outside the occurrence range produces a high AUC value (overfitting), resulting in a misleading evaluation of the model [66]. The model was graded as follows, according to the AUC values: poor (0.6-0.7), fair (0.7-0.8), good (0.8-0.9), or excellent (0.9-1.0) [67]. The TSS accounts for both omission and commission errors, and it is used as an alternative criterion to authenticate model efficiency $[64,68]$. Similarly, the kappa value accesses the accuracy of prediction in comparison with what could have been gained by chance alone [64]. Both the TSS and kappa statistic range from -1 (poor agreement) to +1 (perfect prediction) [64]. We used all three parameters to confirm and validate model performance. Additionally, we performed a jackknife test to quantify the significance of the bioclimatic and environmental variables in the model performance. The binary habitat suitability maps obtained from MaxEnt modeling were used to assess the spatial distribution and spatial invasion of IIAPS. The database and detailed methodology are summarized in a flowchart in Figure 3.

\subsection{Prediction of the Spatial Distribution of IIAPS}

We estimated the areas of the current and future spatial distributions of each IIAPS and calculated the percentage changes for 2050 and 2070 (for both RCP 4.5 and RCP 8.5) relative to the current distribution area. To understand the differences in the spatial distribution and ordering of the samples [69], principal component analysis (PCA) was performed based on the predicted area covered by each IIAPS in the different administrative divisions of South Korea under current and future environmental conditions. The average spatial distributions of IIAPS in different groups were plotted with Map Algebra and the Spatial Analyst tool in ArcGIS 10.3 and compared between the different groups. Percentage changes in the average area for each group in 2050 and 2070 relative to the current area were calculated and expressed in graphical form.

\subsection{Prediction of the Spatial Invasion Risk of IIAPS}

The binary spatial distribution maps of the 10 IIAPS were summed with the Raster 3.4 package in GNU R4.03 to determine an aggregated map of spatial distribution under current and future (RCP 4.5 and RCP 8.5) environmental conditions. The aggregated spatial distribution map was used to estimate the invasion risk map, in which cells with higher species richness indicate high invasion risk and greater potential environmental problems. The current and future spatial invasion risks of the IIAPS were classified into three categories according to the level of species richness in each cell: low risk $(<33 \%)$, moderate risk ( $>33 \%$ to $66 \%$ ), and high risk ( $>66 \%$ to $100 \%)$. We used a linear scale and the method of Ahmad et al. [21], with minor modifications. The areas of low, moderate, and high invasion risk were estimated with the raster calculator in the Spatial Analyst tool in ArcGIS 10.3. We then calculated the area covered by each risk category relative to the country's total area (under both RCP 4.5 and RCP 8.5). Similarly, we calculated the area covered by each risk category within an administrative division relative to the total area of that division, under both RCP 4.5 and 8.5. Moreover, to understand the invasion risk at the local level, we determined the average invasion risk map (under RCP 4.5 and RCP 8.5) for 250 districts using the zonal statistics in the Spatial Analyst tool in ArcGIS 10.3.

\section{Results}

\subsection{Selection and Evaluation of Variables}

To conduct the modeling proposed in this study and to select independent environmental variables, we measured Spearman's correlations among three environmental 
variables and 19 bioclimatic variables (Table S1). Six bioclimatic variables (annual mean temperature, isothermality, temperature seasonality, annual precipitation, precipitation in the wettest month, and precipitation in the driest month) and three environmental variables (distance from roads, distance from water, and land cover change) were ultimately selected for MaxEnt modeling based on their weak correlation with each other $(\mathrm{r}<0.60$; Table S2). These nine variables were considered the most influential factors for the occurrence probability of IIAPS (Table 2).

Table 2. Contribution of bioclimatic and environmental variables in the model.

\begin{tabular}{cccccccccc}
\hline Name of Species & Bio1 & Bio3 & Bio4 & Bio12 & Bio13 & Bio14 & $\begin{array}{c}\text { d- } \\
\text { Road }\end{array}$ & $\begin{array}{c}\text { d- } \\
\text { Water }\end{array}$ & $\begin{array}{c}\text { Land } \\
\text { Cover }\end{array}$ \\
\hline Amorpha fruticosa & $6.15^{\text {a }}$ & 10.73 & 6.72 & 8.54 & 0.76 & 11.28 & 4.09 & 9.51 & 42.22 \\
Coreopsis lanceolata & 8.50 & 4.93 & 10.03 & 7.98 & 3.88 & 2.23 & 8.27 & 9.41 & 44.77 \\
Dactylis glomerata & 6.03 & 5.59 & 12.62 & 0.67 & 20.79 & 5.74 & 3.06 & 1.07 & 44.42 \\
Eragrostis curvula & 23.67 & 13.53 & 32.39 & 2.07 & 8.48 & 6.23 & 1.70 & 0.00 & 11.93 \\
Ageratina altissima & 4.18 & 18.88 & 12.72 & 3.37 & 42.98 & 11.10 & 4.94 & 0.42 & 1.42 \\
Festuca arundinacea & 16.33 & 11.51 & 0.88 & 6.44 & 8.33 & 3.77 & 2.33 & 2.01 & 48.40 \\
Helianthus tuberosus & 8.67 & 1.50 & 12.37 & 2.28 & 0.42 & 0.87 & 2.00 & 2.49 & 69.41 \\
Lolium perenne & 11.83 & 1.15 & 7.71 & 37.50 & 3.72 & 2.40 & 3.73 & 0.52 & 31.42 \\
Medicago sativa & 1.15 & 0.68 & 15.34 & 34.30 & 11.17 & 1.66 & 0.16 & 0.17 & 35.37 \\
Poa pratensis & 2.05 & 11.51 & 5.51 & 14.09 & 8.43 & 14.06 & 1.65 & 1.03 & 41.67
\end{tabular}

a Percentage contribution. The variables Bio1, Bio3, Bio4, Bio12, Bio13, and Bio14 indicate six bioclimatic variables: annual mean temperature, isothermality, temperature seasonality, annual precipitation, precipitation in the wettest month, and precipitation in the driest month, respectively. Similarly, the variables d-road, d-water, and land cover indicate three environmental variables: distance from roads, distance from water, and land cover change, respectively.

Next, we determined the contribution of the nine variables to the MaxEnt model and assessed the degree of importance of each variable in the model. We measured the percent contribution of each variable to model performance using a heuristic approach [70]. In this approach, the contribution of a variable is estimated from the increase in model gain it provides [70]. Among the nine variables selected above, land cover change had the highest relative contribution for seven of the IIAPS [Helianthus tuberosus (69.41\%), Festuca arundinacea $(48.40 \%)$, Coreopsis lanceolata (44.77\%), Dactylis glomerata (44.42\%), Amorpha fruticosa $(42.22 \%)$, Poa pratensis (41.67\%), and Medicago sativa (35.37\%)]. Similarly, Bio04, Bio12, and Bio13 were the most important variables for Eragrostis curvula (32.39\%), Lolium perenne (37.50\%), and Ageratina altissima (42.98\%), respectively (Table 2). These results reveal that land cover change, temperature seasonality, annual precipitation, and precipitation in the wettest month were the most prominent driving factors for the species distribution models of the studied IIAPS; the other variables played minor roles in this study. We assessed variable importance using the jackknife approach [70], which measures how relevant each variable is in explaining species distribution and how much unique information each variable provides [71]. The jackknife test showed that five variables-annual mean temperature, temperature seasonality, annual precipitation, precipitation in the wettest month, and land cover change-were highly correlated in the model (Figure S2a-j).

\subsection{AUC, TSS, and Kappa Values Show Excellent Model Prediction for All IIAPS}

The AUC, TSS, and kappa statistics assessed model performance, presented in Table 3. The average value of AUC was $0.767 \pm 0.054, n=10$, ranging from 0.72 (D. glomerata) to 0.92 (E. rugosum), indicating that the proposed model was sufficiently accurate and that the outputs would be close to the real distribution. The ROC curves for each studied weed are presented in Figure S3a-j. Similarly, the average value of TSS was $0.77 \pm 0.03, n=10$, ranging between 0.72 (F. arundinacea) and 0.85 (C. lanceolata), and the mean kappa value was $0.678 \pm 0.054, n=10$, ranging between 0.57 (D. glomerata) and 0.79 (E. rugosum). These AUC, TSS, and kappa values indicate that the observations may support the predictions provided by the model. 
Table 3. AUC, TSS, and kappa values for each IIAPS in the model calibration.

\begin{tabular}{ccccc}
\hline Name of Species & $\begin{array}{c}\text { No. of Species } \\
\text { Presence Points }\end{array}$ & AUC Value & TSS Value & Kappa Value \\
\hline Amorpha fruticosa & 516 & 0.76 & 0.79 & 0.67 \\
Coreopsis lanceolata & 806 & 0.73 & 0.85 & 0.66 \\
Dactylis glomerata & 634 & 0.72 & 0.81 & 0.57 \\
Eragrostis curvula & 110 & 0.75 & 0.77 & 0.67 \\
Ageratina altissima & 104 & 0.92 & 0.77 & 0.79 \\
Festuca arundinacea & 1076 & 0.73 & 0.72 & 0.64 \\
Helianthus tuberosus & 734 & 0.74 & 0.75 & 0.71 \\
Lolium perenne & 228 & 0.78 & 0.76 & 0.66 \\
Medicago sativa & 242 & 0.76 & 0.74 & 0.68 \\
\hline
\end{tabular}

\subsection{Environmental Changes Positively Regulate the Spatial Distribution of IIAPS in South Korea}

We performed MaxEnt modeling of 10 IIAPS in South Korea, mapped the predicted spatial distributions of each plant species (Figure S1a-j), and estimated the area $\left(\mathrm{km}^{2}\right)$ covered by each plant species both currently and in the future (2050 and 2070), under climate change scenarios RCP 4.5 and RCP 8.5. Under the current environmental conditions, the average IIAPS spatial extent was $33,948 \mathrm{~km}^{2}$, covering $35.74 \%$ of the country's total land surface; M. sativa had the highest coverage at 44,427 $\mathrm{km}^{2}$ (Table 4).

Table 4. Relative change in the spatial distribution of IIAPS in South Korea.

\begin{tabular}{|c|c|c|c|c|c|}
\hline \multirow{2}{*}{ Species Names } & \multirow{2}{*}{ Current $\left(\mathrm{km}^{2}\right)$} & \multicolumn{2}{|c|}{ RCP 4.5} & \multicolumn{2}{|c|}{ RCP 8.5} \\
\hline & & $2050(\%)$ & $2070(\%)$ & $2050(\%)$ & $2070(\%)$ \\
\hline Medicago sativa & 44,427 & -7 & -9 & -10 & -16 \\
\hline Amorpha fruticosa & 38,060 & 43 & 8 & 63 & 23 \\
\hline Dactylis glomerata & 37,565 & 61 & 91 & 42 & 37 \\
\hline Festuca arundinacea & 32,317 & 83 & 34 & 39 & 45 \\
\hline Helianthus tuberosus & 38,656 & 65 & 14 & 33 & 2 \\
\hline Poa pratensis & 34,272 & 41 & 94 & 42 & 66 \\
\hline Coreopsis lanceolata & 30,027 & 98 & 64 & 101 & 98 \\
\hline Eragrostis curvula & 38,113 & 101 & 92 & 59 & 98 \\
\hline Ageratina altissima & 15,725 & 150 & 156 & 45 & 71 \\
\hline Lolium perenne & 30,317 & 74 & 104 & 107 & 145 \\
\hline
\end{tabular}

The model predicted that the spatial distribution of all IIAPS except $M$. sativa would increase in the future under RCP 4.5. The percentage changes in spatial distribution relative to the current distribution were estimated to range from $-7 \%$ to $150 \%$ in 2050 , and from $-9 \%$ to $156 \%$ in 2070 (Table 4). Similarly, under RCP 8.5 , the data show percentage changes in the spatial distributions of $-10 \%$ to $107 \%$ in 2050 and from $-16 \%$ to $145 \%$ in 2070 (Table 4). These results suggest that the spatial distribution of almost all of the tested IIAPS will have increased by both 2050 and 2070. Interestingly, the percentage change in spatial distribution was estimated to be lower under RCP 8.5 than RCP 4.5 for a number of the IIAPS (Table 4). This indicates that the spatial extent of IIAPS may be negatively affected by an extreme increase in global warming.

We performed PCA to determine the ordering of the IIAPS and identified three distinct groups (groups 1,2, and 3) having similar spatial distributions and spread potential (Figure 4). The IIAPS present in group 1 (M. sativa), group 2 (A. fruticose, D. glomerate, F. arundinacea, $H$. tuberosus, and P. pratensis), and group 3 (C. lanceolate, E. curvula, E. rugosum, and L. perenne) had small, intermediate, and large distribution areas, respectively. The average spatial distributions of the IIAPS in each group are presented in Figure S4. We calculated the percentage change in spatial coverage for each group under RCP 4.5 (Figure 5A) and RCP 8.5 (Figure 5B) relative to the current coverage. We found that group 3 had the highest increase in 2050 (increases up to $92.8 \%$ ) and in 2070 (increases up to 102\%). 
Group 1 had the lowest percentage change with estimated reductions in the average spatial distribution in 2050 (up to $-10 \%$ ) and 2070 (up to $-16 \%$ ).

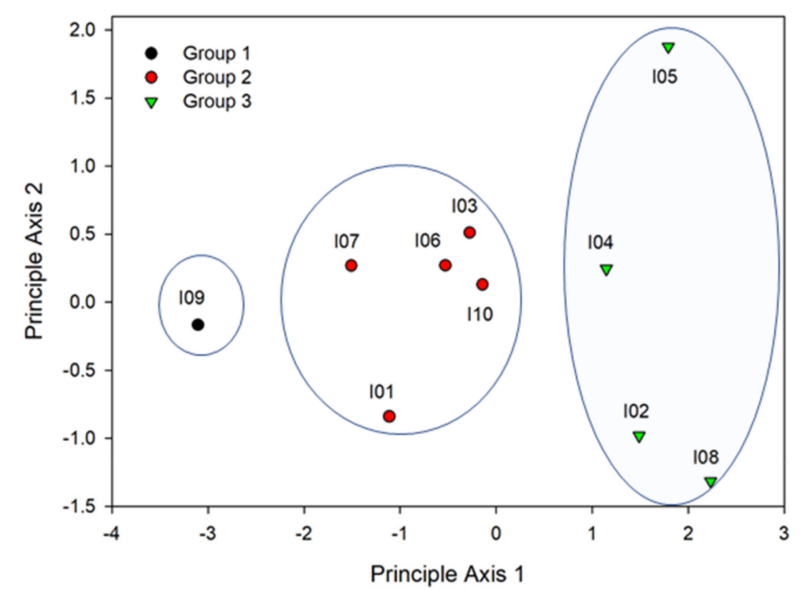

Eigenvectors

\begin{tabular}{|c|c|c|c|}
\hline Future scenarios & Year & PC1 & PC2 \\
\hline \multirow{2}{*}{ RCP 4.5} & 2050 & 0.476 & 0.494 \\
\cline { 2 - 4 } & 2070 & 0.499 & 0.472 \\
\hline \multirow{3}{*}{ RCP 8.5} & 2050 & 0.461 & -0.669 \\
\cline { 2 - 4 } & 2070 & 0.558 & -0.292 \\
\hline
\end{tabular}

Figure 4. Principal component analysis reveals the grouping of introduced alien plant species based on the extent of their spatial distribution. The scientific and common names of the introduced alien plants (I01-I10) are presented in Table 1.

\subsection{Environmental Changes Increase the Spatial Invasion Risk of IIAPS in South Korea}

Invasion risk estimates reveal that a non-native species can become established in a novel ecosystem, either deliberately or haphazardly, thereby threatening the surrounding native biodiversity. Here, we estimated the invasion risk of IIAPS based on the number of introduced alien plant species present in a cell: cells with a higher number of IIAPS were considered to be at a higher risk of invasion. We classified the results into three categories of risk (low, moderate, and high). The overall invasion risk maps calculated from the 10 IIAPS under current and future (RCP 4.5 and RCP 8.5) environmental conditions are presented in Figure 6.

Under current conditions, the risk of invasion was predicted to be high in three provinces [Gyeonggi (e.g., Gimpo-si and Ilsanseo-gu of Goyang-si), Jeollabuk (e.g., Gimjesi and Iksan-si), and Jeollanam (e.g., Mokpo-si)] and four metropolitan cities [Seoul (e.g., Seongdong-gu and Dongdaemun-gu), Busan (e.g., Gangseo-gu), Ulsan (e.g., Nam-gu), and Gwangju (e.g., Seo-gu)] (Figures 6A and 7A), covering an estimated $31.51-70.31 \%$ of the corresponding provinces and cities (Table 5). However, the risk of invasion was estimated to be low to moderate in the northern part of Gyeonggi province and across most of the Gangwon and Jeju provinces (Figure 6A).

Future environmental change increased the extent and intensity of the IIAPS invasion in South Korea for both 2050 and 2070 (Figure 6B,C). The model predicted that most IIAPS would retain the current spatial distribution and add significant additional suitable habitat; therefore, the risk of invasion would be moderate to high across most of Gyeongsangnam province, Gyeongsangbuk province, Chungcheongbuk province, central parts of Chungcheongnam province, three metropolitan cities (Daegu, Daejeon, and Sejong), and southern parts of Gangwon province (Figure $6 \mathrm{~B}, \mathrm{C}$ and Figure $7 \mathrm{~B}, \mathrm{C}$ ). These provinces and metropolitan cities would have a high risk of invasion (up to $79.15 \%$ ) by 2050 and 2070 (Table 5). These results indicate that future environmental changes may lead to expanded 
spatial invasion of IIAPS from the south coast and west coast areas toward the central and northern regions.
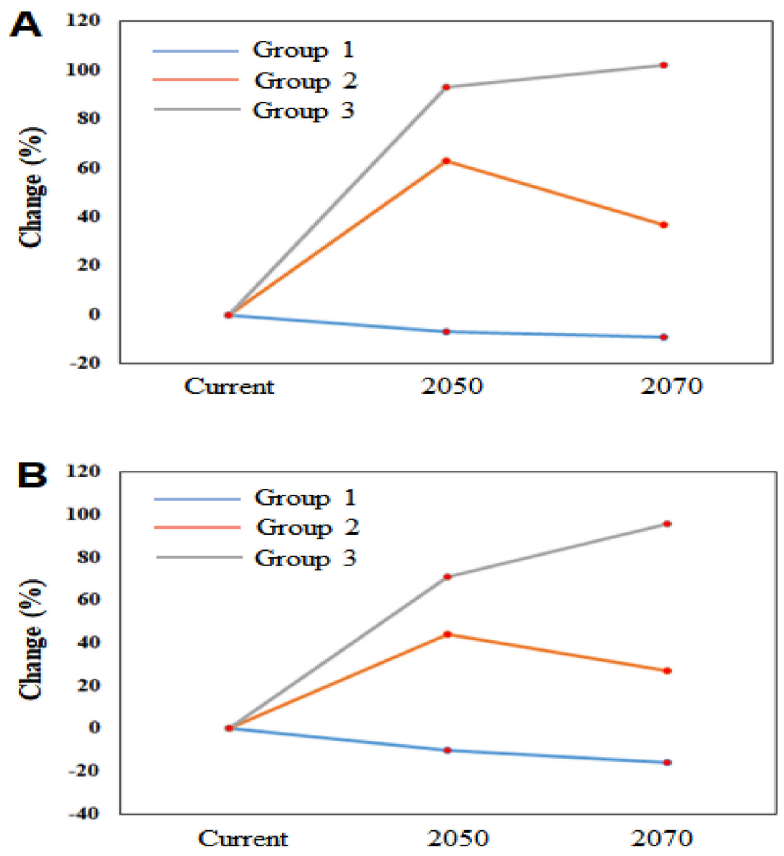

Figure 5. Percentage change in the extent of the average spatial distribution of alien plant species in group 1, group 2, and group 3, under the climate change scenarios RCP 4.5 (A) and RCP 8.5 (B). The details of each group are presented in Table 1.

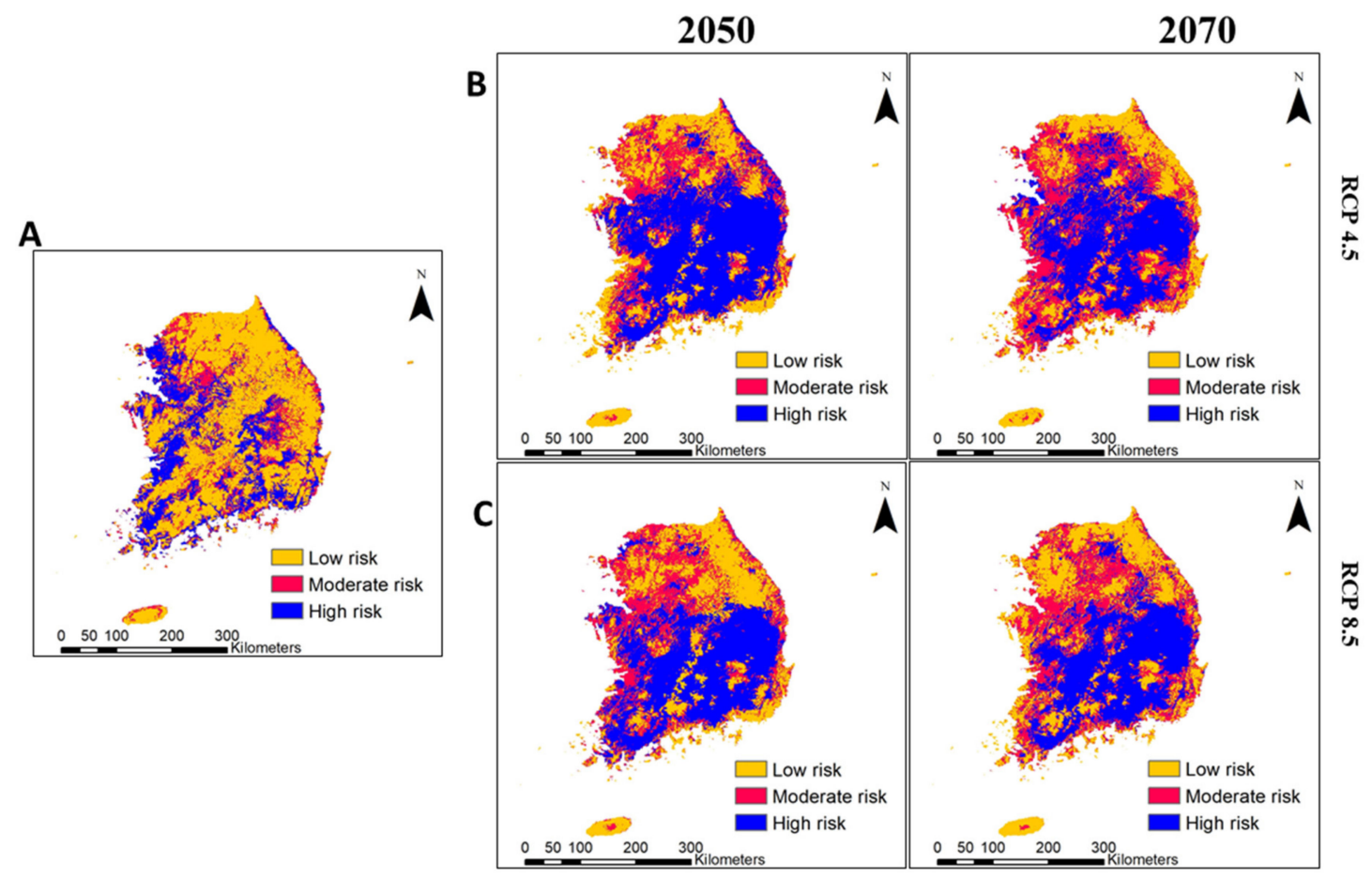

Figure 6. Predicted invasion risk of introduced alien plants in South Korea. The invasion risk assessment is divided into three categories: low, moderate, and high. These three categories are indicated by yellow, red, and blue in the figure. Spatial invasion predictions under the current $(\mathbf{A})$ and future $(\mathbf{B}, \mathbf{C})$ environmental conditions in South Korea. 
A

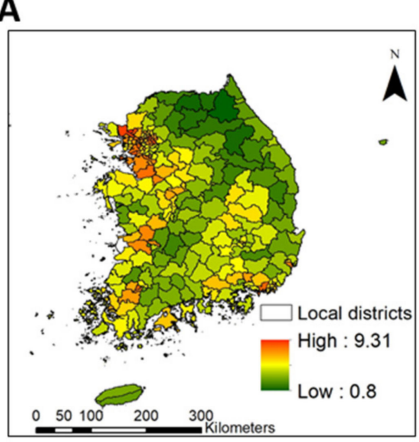

2050

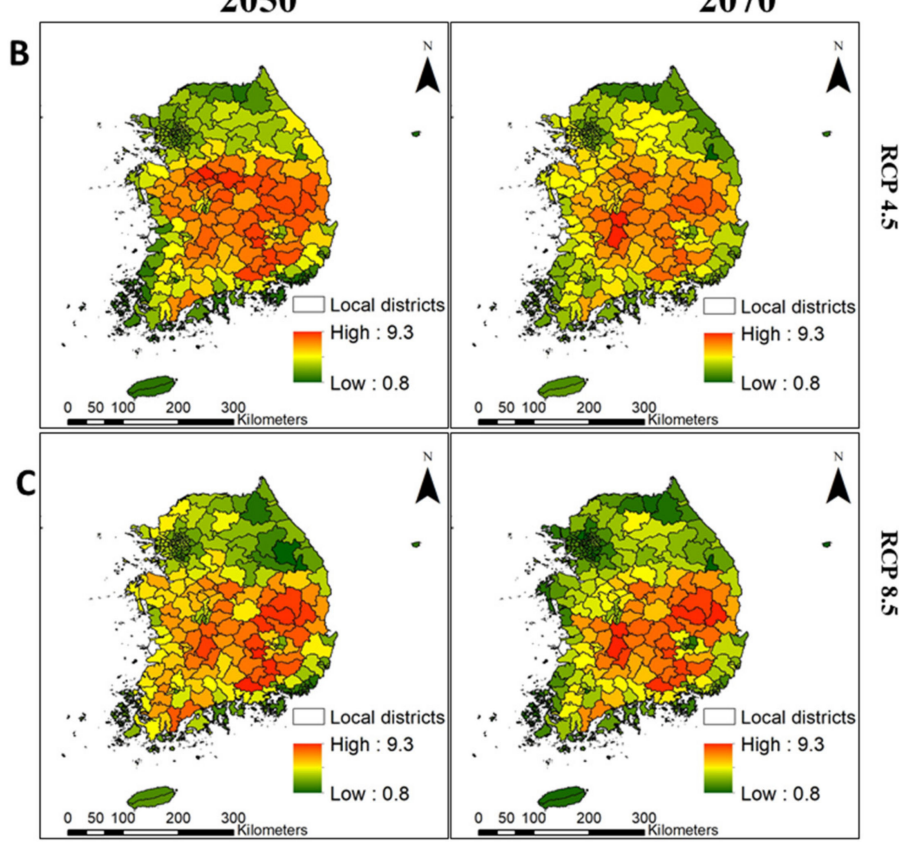

Figure 7. Average invasion risk at the district level under the current $(\mathbf{A})$ and future $(\mathbf{B}, \mathbf{C})$ environmental conditions in South Korea. The red colors in the figure indicate the highest average invasion risk, and the green colors indicate the lowest average invasion risk.

Table 5. Area in each invasion risk category relative to the total area of the province or major city, under current and predicted environmental changes in South Korea.

\begin{tabular}{|c|c|c|c|c|c|c|c|c|c|c|}
\hline \multirow{2}{*}{ Provinces } & \multirow{2}{*}{$\begin{array}{c}\text { Total Area } \\
\left(\mathrm{Km}^{2}\right)^{a}\end{array}$} & \multicolumn{3}{|c|}{ Current $(\%)^{b}$} & \multicolumn{3}{|c|}{$2050(\%)^{c}$} & \multicolumn{3}{|c|}{$2070(\%)^{d}$} \\
\hline & & Low & Moderate & High & Low & Moderate & High & Low & Moderate & High \\
\hline Gangwon & $16,503.73$ & 72.21 & 20.62 & 6.94 & 36.78 & 45.29 & 17.93 & 36.15 & 41.67 & 22.18 \\
\hline Gyeonggi & 9810.10 & 30.64 & 33.41 & 35.68 & 16.34 & 60.51 & 23.14 & 21.34 & 53.88 & 24.78 \\
\hline Incheon & 614.89 & 17.27 & 34.32 & 45.63 & 16.53 & 71.34 & 12.13 & 23.68 & 63.59 & 12.74 \\
\hline Seoul & 605.70 & 6.18 & 23.51 & 70.31 & 21.95 & 75.84 & 2.21 & 32.75 & 67.09 & 0.16 \\
\hline Gyeongsangbuk & $18,922.94$ & 48.49 & 23.36 & 28.13 & 6.73 & 14.12 & 79.15 & 5.73 & 22.07 & 72.20 \\
\hline Chungcheongbuk & 7415.68 & 50.23 & 20.74 & 29.02 & 8.09 & 18.47 & 73.44 & 4.73 & 23.22 & 72.05 \\
\hline Chungcheongnam & 7637.76 & 39.75 & 20.54 & 39.60 & 8.20 & 23.58 & 68.22 & 11.81 & 35.51 & 52.69 \\
\hline Sejong & 465.24 & 21.33 & 21.74 & 56.93 & 2.77 & 18.53 & 78.70 & 5.27 & 30.39 & 64.35 \\
\hline Daejeon & 539.55 & 38.72 & 19.04 & 42.24 & 19.17 & 52.54 & 28.28 & 9.71 & 44.62 & 45.67 \\
\hline Jeollabuk & 7716.82 & 47.17 & 16.15 & 36.67 & 9.28 & 22.07 & 68.65 & 6.25 & 26.89 & 66.87 \\
\hline Daegu & 880.84 & 46.35 & 16.02 & 37.63 & 24.38 & 31.27 & 44.34 & 26.64 & 45.33 & 28.03 \\
\hline Gyeongsangnam & 9809.70 & 39.45 & 25.01 & 35.46 & 18.30 & 17.55 & 64.15 & 7.53 & 32.56 & 59.92 \\
\hline Ulsan & 1029.49 & 40.58 & 27.72 & 31.51 & 27.03 & 42.72 & 30.25 & 19.73 & 58.85 & 21.42 \\
\hline Jeollanam & $10,180.34$ & 46.09 & 17.38 & 36.24 & 20.79 & 32.52 & 46.69 & 18.59 & 47.81 & 33.60 \\
\hline Busan & 673.03 & 29.86 & 16.86 & 53.28 & 80.23 & 18.14 & 1.63 & 16.04 & 76.83 & 7.13 \\
\hline Gwangju & 498.36 & 24.85 & 10.77 & 64.37 & 19.74 & 29.56 & 50.70 & 19.17 & 34.78 & 46.05 \\
\hline Jeju & 1674.96 & 45.33 & 54.26 & 0.18 & 57.71 & 42.29 & 0.00 & 59.84 & 40.15 & 0.00 \\
\hline
\end{tabular}

a , Estimated area of the different provinces and major cities in South Korea. ${ }^{b, c, d}$, The average percentage across the results for RCP 4.5 and RCP 8.5.

Under current conditions, the proportions of areas estimated to be at low, moderate, and high risk comprise $47.96 \%, 22.88 \%$, and $29.14 \%$ of the country's total land mass, respectively (Figure $8 \mathrm{~A}$ ). Our study predicts that $82.36 \%$ and $86.21 \%$ of the country's total area may be at moderate or high risk of invasion by 2050 and 2070, respectively, under RCP 4.5 (Figure 8 A). Similarly, under RCP $8.5,81.31 \%$ and $80.99 \%$ of the country's total area may be at moderate or high risk of IIAPS invasion by 2050 and 2070, respectively (Figure 8B). These results show that the rate of spatial invasion by IIAPS may increase significantly in South Korea with future environmental changes. 


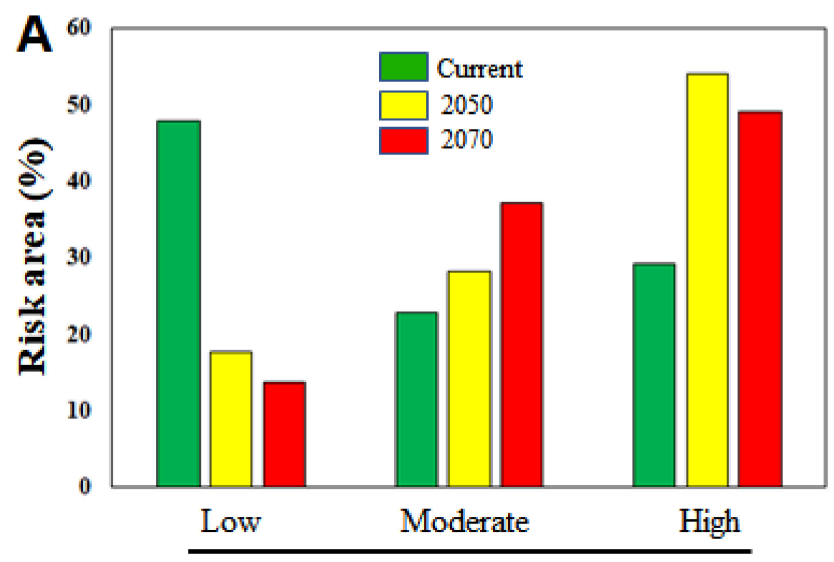

Spatial invasion risk

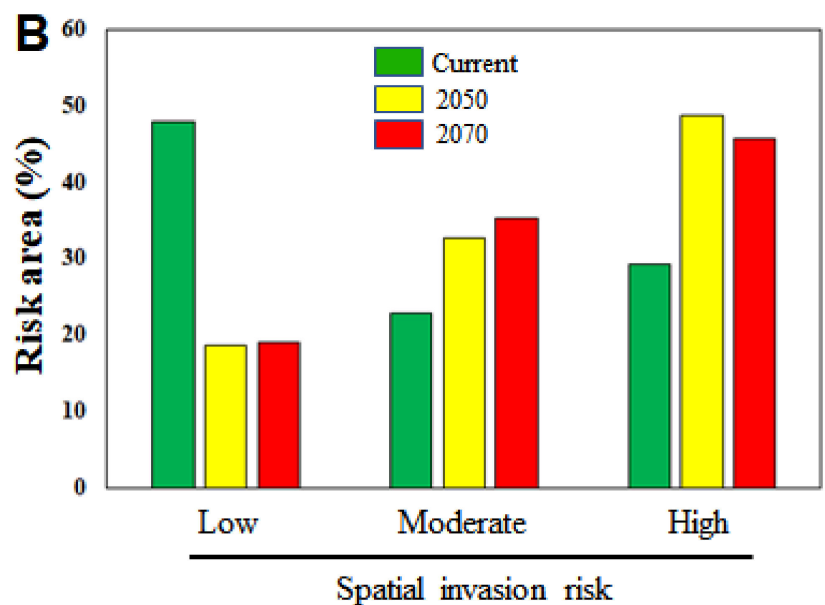

Figure 8. Estimates of the area assigned to different categories of invasion risk relative to the total area of South Korea. The numbers on the $y$-axis indicate the percentage area categorized as at low, moderate, or high risk of invasion under current and future environmental conditions. (A) RCP 4.5 and (B) RCP 8.5 .

\section{Discussion}

Our study provides several prominent findings, as follows: (1) Of the nine environmental variables used in the model, land cover change was the most important for the future spatial distribution of IIAPS (Table 2). (2) Under future scenarios of environmental change in South Korea, alien plant species introduced for a particular purpose will not remain limited to the introduced area but will spread and invade non-targeted ecosystems, including croplands, pasture, and forest. (3) Current invasion risk is estimated to be high in the coastal areas and some densely populated metropolitan cities (e.g., Seoul, Busan, and Gwangju; Figure 6A) but, in the future, invasion risk is predicted to increase in the central and northern regions, leading to approximately $86.21 \%$ of the total area of the country being at high or moderate risk of invasion (Figure 6B,C). (4) Extreme climate change may not be favorable overall to alien and invasive species: the relative change in IIAPS coverage was generally lower under climate change scenario RCP 8.5 than under RCP 4.5 (Table 4).

Of the total number of alien and invasive plant species recorded in South Korea, 25.31\% were intentionally introduced into the country [27]. The alien plants have been intentionally introduced into South Korea for a variety of purposes, including erosion control in the mountains (e.g., A. fruticose, C. lanceolate, and E. curvula), grassland management for commercial livestock farming (e.g., M. sativa, F. arundinacea, and L. perenne), ornamental use (e.g., E. rugosum), and medical use (e.g., H. tuberosus; Table 1) [27]. These species can become well adapted, cultivated, and naturalized in local and systemic areas $[13,20,55,72]$. 
Some now exist as ruderal species colonizing disturbed land, such as roads, shorelines, mining sites, and recreational parks [27,29]. Ironically, the ecological niches of these species trigger their negative effects on agriculture, horticulture, native ecosystems, the economy, crop production, livestock, and wild ungulates [73]. E. rugosum is now listed as the most ecologically disruptive weed in South Korea [27], and other species may become serious threats to the natural ecosystem. With these phenomena on the rise in South Korea, the issues of how to monitor IIAPS, predict their spatial distribution and manage invasion risk are being raised. Therefore, modern modeling systems are now an essential tool for protecting the natural ecosystem.

MaxEnt is a presence-only modeling approach that is suitable for cases in which true absence data is lacking. It is commonly used for modeling invasive species because such species' ranges are increasing and have not yet reached equilibrium; the absence of data for invasive species is therefore untrustworthy and may lead to incorrect interpretation $[32,33]$. MaxEnt is a generative strategy that uses environmental data from across the study area rather than a discriminative approach and has the advantage of being more efficient when presence data are not sufficient [74]. The MaxEnt model produces robust estimates of climatically suitable habitats for invasive species at small spatial scales and with a limited dataset $[75,76]$. Although recent developments are attempting to solve some of the limitations of MaxEnt modeling, major drawbacks remain, including the risk of overfitting, which limits the model's ability to generalize well to new data. The 'regularization multiplier' parameter in MaxEnt attempts to solve this by reducing the model's complexity, resulting in a less localized prediction [32]. Another important drawback to MaxEnt modeling is the accuracy of presence-only modeling related to biases in the species occurrence localities. This study spatially rarefied the presence points using the Arc GIS SDM toolbox 2.4 to reduce species occurrence biases.

In addition to MaxEnt, the most popular machine-learning models for studying species distribution are artificial neural networks (ANNs), random forests (RFs), and genetic algorithms for rule-set production (GARPs). These models are powerful tools for solving complex dependencies, and both numerical and categorical environmental variables can be used as input variables in such models [77]. An ANN consists of a network of artificial neurons or nodes, and all information transfer between neurons is weighted. ANNs can operate like multiple regressions, and their accuracy is controlled by the weight decay of the links and the number of hidden neurons [77]. They show good performance with complicated species-environment relationships. RFs are multi-decision tree ensemble classifiers that use Breiman's random forest algorithm for classification and regression [78]. They are unaffected by multicollinearity, excel at dealing with correlated variables, and run efficiently with large databases [76,78]. Similarly, GARPs are SDMs that use a genetic algorithm to create random mathematical rules that can be interpreted as limiting environmental circumstances and specific species-environment correlations [77,79]. Each rule is treated as a gene and sets of genes are combined at random to build a large number of models reflecting the possibility of species occurrence [77]. Although all the models described above have their own unique properties for predicting ecological niches, MaxEnt is considered an effective SDM tool for robust predictions across many species and regions. It is also relatively user-friendly as the software can import GIS layers of environmental variables directly using presence-only species occurrence data with default settings; less effort needs to be paid to parameter tuning [32,33,74].

Because of the current situation, we attempted to develop a modeling system that could monitor and estimate the spatial distribution and invasion risk of 10 IIAPS using MaxEnt. The results revealed that all IIAPS in our study except $M$. sativa would retain their current ecological niches and add additional areas to their spatial distribution in South Korea. However, the rate and extent of increasing coverage are not estimated to be consistent among all IIAPS. D. glomerata, E. curvula, and E. rugosum are estimated to have relatively high spatial coverage, up to $80.85 \%$ and $77.10 \%$ of the total land area of South Korea in 2050 and 2070, respectively (under RCP 4.5). These predictions are comparable 
to the results from earlier studies performed in South Korea $[49,55,80]$. Similarly, we estimated the risk of invasion by the IIAPS and found that $12 \%$ of the country is currently at high risk of invasion and that this area is likely to increase dramatically by 2050 (to $39 \%$ ) and 2070 (to 50\%), under RCP 4.5. For all IIAPS, the increased invasion risk with environmental change expanded in eastward and northward directions, invading major agricultural pocket zones (e.g., Jeollabuk, Jeollanam, and Chungcheongnam provinces), most of the national parks, and protected areas, including the Baekdudaegan mountain range $(701 \mathrm{~km})$ [48], which are biodiversity hotspots and the natural habitat of 297 species of endemic plants (e.g., Abies koreana, Berberis koreana, and Arabis columnaris) [81,82]. Moreover, global climate change is likely to increase the capacity of alien plant species to invade into new areas while lowering native community resistance to invasion by disrupting the dynamic equilibria that maintain native communities [16]. Among the various climatic variables, temperature seasonality and annual precipitation are the dominant factors affecting the spatial distribution of many IIAPS (Table 2).

The results supported by many other studies have similarly attempted to model the invasion risk of non-native species in South Korea and across the globe. For example, Dullinger et al. [83] estimated that future climate and land cover changes in Europe would increase the risk of naturalization of non-native garden plants by up to $102 \%$ under RCP 8.5 . Bai et al. conducted a spatial invasion risk assessment of alien invasive plants in China and found that the southern part of China will be at high risk of invasion in the future, with drought-resistant species becoming dominant in the natural ecosystems. In the eastern United States, Bradley et al. [13] estimated the invasion risk of three invasive plants, Pueraria lobata, Ligustrum sinense, and Imperata cylindrical. They showed that climate change is likely to allow significant expansion of their ranges. Similarly, risk assessment of the invasive weed Leucanthemum vulgare under future climate change showed it would be distributed in all continents, with the Oceania region being at particularly high risk [21] Adhikari et al. [49] and Hong et al. [55] estimated rapid range expansion of invasive species in South Korea under future climate change. These studies demonstrate that future climate change will be a major factor in the proliferation of non-native plants across the world, consistent with our findings.

Plant invasion is thought to be boosted by soil disturbance induced by anthropogenic land cover changes, which accelerate ecosystem disruption and favor introducing invasive species over native species [84]. In South Korea, land use patterns have been changing for a long time. Specific examples of major land cover changes in South Korea include the expansion of road and rail networks, implementation of upland farming practices, forest fragmentation for urbanization, and increased industrialization [30]. Although the transportation network is part of the fundamental infrastructure of the country, without careful design and management of the roads, they may be a source for the introduction and dispersal of alien plant species into new areas $[25,85]$. In South Korea, the total length of roads and railways that are expected to increase plant invasion has been measured at $116,850.6 \mathrm{~km}$ [86]. Understanding the impact of land cover changes on ecological niche availability is crucial to prognosticating invasion and managing landscapes to minimize the spread of invasive species $[24,25]$. Currently, the spatial distribution of these species is concentrated close to the coastal areas in the western and southern regions: we predict that the distributions will expand toward the central and northern regions by 2050 and 2070, related to the transportation corridors to these regions. Thus, land cover changes and climatic variables may play pivotal roles in the spatial distribution of IIAPS, as suggested by the modeling system used in this study and by previous research $[49,55]$.

Our findings provide spatially explicit evidence that supports the earlier hypothesis that warming temperatures will increase the northward spread of alien and invasive plant habitats [87]. These results demonstrate that future environmental changes, including climate change and land cover change, are likely to favor IIAPS in South Korea. Therefore, the future spatial distribution and invasion risk of IIAPS will be exacerbated on a large scale, threatening the native biodiversity and imperiling the native ecosystem of South 
Korea [13,55]. In addition to the environmental factors described in this study, the introduction history, biogeographic origin, and biological traits of IIAPS are strongly correlated with invasion success [88]. The biological traits that are correlated with invasiveness include relative growth rate [89], seed mass, the maximum height of the plant, and plasticity [90]. Plants with shorter life cycles usually have higher reproduction rates and may evolve more quickly to adapt to new environments, improving invasion success [91]. Similarly, the physiological characteristics of alien plants, such as their photosynthetic rate, resource utilization efficiency, and tolerance to environments from humid to xeric, play important roles in their invasion success [88]. Therefore, biological and physiological traits should be incorporated during the modeling of IIAPS to obtain the most accurate model predictions. Other important parameters for prediction include the soil characteristics, land topography, biotic interactions (e.g., competition and facilitation), and vectors driving species invasion, as suggested by Buri et al. [92] and Pysek and Richardson [93]. Although diverse variables were included in our model to improve accuracy, these other variables should be analyzed further in future studies to obtain more precise predictions.

\section{Conclusions}

IIAPS can negatively affect a variety of fields in South Korea, including agriculture, the economy, industry, horticulture, and the natural ecosystem. As part of efforts to overcome this, we developed a MaxEnt prediction model to estimate the spatial distribution and invasion risk of IIAPS under current and future environmental changes. Our findings suggest that the spatial distributions of IIAPS are estimated to enlarge extensively in the future while retaining their existing ecological niches, and that, currently, the southern and western coastal regions and some metropolitan cities, such as Seoul, Busan, and Daegu, are at relatively high risk of invasion by IIAPS. In addition, climate change due to global warming and other environmental changes is likely to increase invasion risk in the country. Taken together, our results strongly suggest that this modeling system can help to prioritize the invasive weeds and geographical regions to be targeted in a timely fashion, as well as support government authorities in adopting the best preventive measures. For example, our system can be used to support efforts to eradicate small populations of IIAPS detected in non-target areas that are likely to become sources for future expansion.

Supplementary Materials: The following are available online at https://www.mdpi.com/article/10 .3390/biology10111169/s1, Table S1. Spearman correlation for bioclimatic variables. Table S2. List of bioclimatic and environmental variables used in this study. Figure S1a-j. Spatial distribution of intentionally introduced alien plant species in South Korea. S1a, Amorpha fruticosa; S1b, Coreopsis lanceolata; S1c, Dactylis glomerata; S2d, Eragrostis curvula; S1e, Ageratina altissima; S1f, Festuca arundinacea; S1g, Helianthus tuberosus; S1h, Lolium perenne; S1i, Medicago sativa; S1j, Poa pratensis. Figure S2a-j. Jackknife test results indicate the relative contribution of each environmental variable in the modeling for different intentionally introduced alien plant species. S2a, Amorpha fruticosa; S2b, Coreopsis lanceolata; S2c, Dactylis glomerata; S2d, Eragrostis curvula; S2e, Ageratina altissima; S2f, Festuca arundinacea; $\mathrm{S} 2 \mathrm{~g}$, Helianthus tuberosus; S2h, Lolium perenne; S2i Medicago sativa; S2j, Poa pratensis. Figure S3a-j. The area under the receiver operating characteristics (ROC) curve (AUC) to determine the model's goodness-of-fit under the current climatic conditions. S1a, Amorpha fruticosa; S3b, Coreopsis lanceolata; S3c, Dactylis glomerata; S3d, Eragrostis curvula; S3e, Ageratina altissima; S3f, Festuca arundinacea; S3g, Helianthus tuberosus; S3h, Lolium perenne; S3i, Medicago sativa; S3j, Poa pratensis. Figure S4. Comparative analyses of the average spatial distribution of intentionally introduced alien plant species (IIAPS) categorized into three groups under the predicted environmental changes in South Korea.

Author Contributions: Conceptualization, P.A., Y.-H.L. and S.-H.H.; methodology, P.A. and Y.-H.L.; software, P.A.; validation, P.A.,Y.-H.L., Y.-S.P.; formal analysis, P.A.; investigation, P.A., Y.-H.L. and Y.-S.P.; resources, S.-H.H.; data curation, P.A.; writing-original draft preparation, P.A.; writingrewriting original draft, P.A. and Y.-S.P.; writing-review and editing, P.A. and Y.-S.P.; supervision, Y.-S.P. and S.-H.H.; project administration, S.-H.H.; funding acquisition, S.-H.H. All authors have read and agreed to the published version of the manuscript. 
Funding: This study was supported by the Ministry of Environment, Republic of Korea (grant number 2018002270002).

Institutional Review Board Statement: Not applicable.

Informed Consent Statement: Not applicable.

Data Availability Statement: Not applicable.

Acknowledgments: We are grateful to the Korea Meteorological Agency for providing the maximum and minimum temperature and average precipitation data for South Korea.

Conflicts of Interest: The authors declare no conflict of interest.

\section{References}

1. Ansong, M.; Pickering, C. What'sa weed? Knowledge, attitude and behaviour of park visitors about weeds. PLoS ONE 2015, 10, e0135026. [CrossRef]

2. Parker, C. Parasitic weeds: A world challenge. Weed Sci. 2012, 60, 269-276. [CrossRef]

3. IUCN. Invasive Alien Species and Cliamte Change. Available online: http://iucn.org (accessed on 28 August 2021).

4. Cook, G.D.; Dias, L. It was no accident: Deliberate plant introductions by Australian government agencies during the 20th century. Aust. J. Bot. 2006, 54, 601-625. [CrossRef]

5. Van Klinken, R.D.; Friedel, M.H. Unassisted invasions: Understanding and responding to Australia's high-impact environmental grass weeds. Aust. J. Bot. 2018, 65, 678-690. [CrossRef]

6. Keller, R.P.; Geist, J.; Jeschke, J.M.; Kühn, I. Invasive species in Europe: Ecology, status, and policy. Environ. Sci. Eur. 2011, 23, 23. [CrossRef]

7. Divíšek, J.; Chytrý, M.; Beckage, B.; Gotelli, N.J.; Lososová, Z.; Pyšek, P.; Richardson, D.M.; Molofsky, J. Similarity of introduced plant species to native ones facilitates naturalization, but differences enhance invasion success. Nat. Commun. 2018, 9, 4631. [CrossRef]

8. Ordonez, A.; Wright, I.J.; Olff, H. Functional differences between native and alien species: A global-scale comparison. Funct. Ecol. 2010, 24, 1353-1361. [CrossRef]

9. Richardson, D.M.; Pyšek, P. Naturalization of introduced plants: Ecological drivers of biogeographical patterns. New Phytol. 2012, 196, 383-396. [CrossRef] [PubMed]

10. Weber, E. Invasive Plant Species of the World: A Reference Guide to Environmental Weeds; CABI: Potsdam, Germany, 2017.

11. Fletcher, D.; Gillingham, P.; Britton, J.; Blanchet, S.; Gozlan, R.E. Predicting global invasion risks: A management tool to prevent future introductions. Sci. Rep. 2016, 6, 26316. [CrossRef]

12. Fahad, S.; Hussain, S.; Chauhan, B.S.; Saud, S.; Wu, C.; Hassan, S.; Tanveer, M.; Jan, A.; Huang, J. Weed growth and crop yield loss in wheat as influenced by row spacing and weed emergence times. Crop Protect. 2015, 71, 101-108. [CrossRef]

13. Bradley, B.A.; Wilcove, D.S.; Oppenheimer, M. Climate change increases risk of plant invasion in the Eastern United States. Biol. Invasions 2010, 12, 1855-1872. [CrossRef]

14. Paini, D.R.; Sheppard, A.W.; Cook, D.C.; De Barro, P.J.; Worner, S.P.; Thomas, M.B. Global threat to agriculture from invasive species. Proc. Natl. Acad. Sci. USA 2016, 113, 7575-7579. [CrossRef]

15. Walsh, J.R.; Carpenter, S.R.; Vander Zanden, M.J. Invasive species triggers a massive loss of ecosystem services through a trophic cascade. Proc. Natl. Acad. Sci. USA 2016, 113, 4081-4085. [CrossRef]

16. Thuiller, W.; Richardson, D.M.; Midgley, G.F. Will climate change promote alien plant invasions. In Biological Invasions; Springer: Berlin/Heidelberg, Germany, 2008; pp. 197-211.

17. Weltzin, J.F.; Belote, R.T.; Sanders, N.J. Biological invaders in a greenhouse world: Will elevated $\mathrm{CO}_{2}$ fuel plant invasions? Front. Ecol. Environ. 2003, 1, 146-153. [CrossRef]

18. Debouk, H.; de Bello, F.; Sebastià, M.-T. Functional trait changes, productivity shifts and vegetation stability in mountain grasslands during a short-term warming. PLOS ONE 2015, 10, e0141899.

19. Rasmussen, K.; Thyrring, J.; Muscarella, R.; Borchsenius, F. Climate-change-induced range shifts of three allergenic ragweeds (Ambrosia L.) in Europe and their potential impact on human health. Peer] 2017, 5, e3104. [CrossRef]

20. Hellmann, J.J.; Byers, J.E.; Bierwagen, B.G.; Dukes, J.S. Five potential consequences of climate change for invasive species. Conserv. Biol. 2008, 22, 534-543. [CrossRef]

21. Ahmad, R.; Khuroo, A.A.; Charles, B.; Hamid, M.; Rashid, I.; Aravind, N. Global distribution modelling, invasion risk assessment and niche dynamics of Leucanthemum vulgare (Ox-eye Daisy) under climate change. Sci. Rep. 2019, 9, 11395. [CrossRef]

22. IPCC. Climate Change 2013: The Physical Science Basis. Contribution of Working Group I to the Fifth Assessment Report of the Intergovernmental Panel on Climate Change; IPCC: Geneva, Switzerland, 2013; p. 1535.

23. Manzoor, S.A.; Griffiths, G.; Lukac, M. Land use and climate change interaction triggers contrasting trajectories of biological invasion. Ecol. Indic. 2021, 120, 106936. [CrossRef]

24. Vila, M.; Ibáñez, I. Plant invasions in the landscape. Landsc. Ecol. 2011, 26, 461-472. [CrossRef] 
25. Wang, W.; Zhang, C.; Allen, J.M.; Li, W.; Boyer, M.A.; Segerson, K.; Silander, J.A. Analysis and prediction of land use changes related to invasive species and major driving forces in the state of Connecticut. Land 2016, 5, 25. [CrossRef]

26. Mosher, E.S.; Silander, J.A.; Latimer, A.M. The role of land-use history in major invasions by woody plant species in the northeastern North American landscape. Biol. Invasions 2009, 11, 2317-2328. [CrossRef]

27. Young, J.S.; Shin, H.T.; Kim, S.J.; An, J.B.; Heo, T.I.; Chung, J.M.; Cho, Y.C. Invasive Alien Plants in South Korea; Korea National Arboretum: Pocheon, Korea, 2017.

28. NIE. Monitoring of Invasive Alien Species Designated by the Act on the Conservation and Use of Biological Diversity (IV); National Institute of Ecology: Seocheon-gun, Korea, 2017.

29. Lee, I.-Y.; Oh, Y.-J.; Hong, S.-H.; Heo, S.-J.; Lee, C.-Y.; Park, K.W.; Cho, S.-H.; Kwon, O.-D.; Im, I.-B.; Kim, S.-K. Occurrence of weed flora and changes in weed vegetation in orchard fields of Korea. Weed Turfgrass Sci. 2017, 6, 21-27. [CrossRef]

30. Jongchul Park, J.K. Land Use and land Cover. 2021. Available online: http://nationalatlas.ngii.go.kr/pages/page_756.php (accessed on 11 November 2021).

31. Choung, Y.-J. Land cover change detection in the Nakdong river basin using LiDAR data and multi-temporal landsat imagery. $J$. Korean Assoc. Geogr. Inf. Stud. 2015, 18, 135-148. [CrossRef]

32. Phillips, S.J.; Dudík, M. Modeling of species distributions with Maxent: New extensions and a comprehensive evaluation. Ecography 2008, 31, 161-175. [CrossRef]

33. Phillips, S.J.; Anderson, R.P.; Schapire, R.E. Maximum entropy modeling of species geographic distributions. Ecol. Model. 2006, 190, 231-259. [CrossRef]

34. Kang, E.S.; Lee, S.-R.; Oh, S.H.; Kim, D.-K.; Jung, S.-Y.; Son, D.C. Comprehensive review about alien plants in Korea. Korean J. Plant Taxon. 2020, 50, 89-119. [CrossRef]

35. Jiménez-Valverde, A.; Peterson, A.T.; Soberón, J.; Overton, J.M.; Aragón, P.; Lobo, J.M. Use of niche models in invasive species risk assessments. Biol. Invasions 2011, 13, 2785-2797. [CrossRef]

36. NIBR. Korean Red List of Threatened Species, 2nd ed.; Min-Hwan Suh, B.-Y.L., Kim, S.T., Park, C.-H., Oh, H.-K., Kim, H.-Y., Lee, J.-H., Lee, S.-Y., Eds.; National Institute of Biological Resources, Ministry of Environment: Incheon, Korea, $2014 ;$ p. 242.

37. Koo, K.A.; Kong, W.S.; Nibbelink, N.P.; Hopkinson, C.S.; Lee, J.H. Potential effects of climate change on the distribution of cold-tolerant evergreen broadleaved woody plants in the Korean Peninsula. PLoS ONE 2015, 10, e0134043. [CrossRef]

38. KMA. Climate of Korea; KMA: Seoul, Korea, 2021; Available online: http:/ / web.kma.go.kr (accessed on 27 August 2021).

39. NIER. The Second and Third National Ecosystem Survey: 1997-2012; National Institute of Environmental Research: Incheon, Korea, 2013.

40. Brown, J.L.; Bennett, J.R.; French, C.M. SDMtoolbox 2.0: The next generation Python-based GIS toolkit for landscape genetic, biogeographic and species distribution model analyses. PeerJ 2017, 5, e4095. [CrossRef]

41. Boria, R.A.; Olson, L.E.; Goodman, S.M.; Anderson, R.P. Spatial filtering to reduce sampling bias can improve the performance of ecological niche models. Ecol. Model. 2014, 275, 73-77. [CrossRef]

42. Busby, J. Bioclim, a bioclimatic analysis and prediction system. In Nature Conservation: Cost Effective Biological Surveys and Data Analysis; Margules, C., Austin, M., Eds.; CSIRO: Canberra, Australia, 1991; pp. 64-68.

43. Amiri, M.; Tarkesh, M.; Jafari, R.; Jetschke, G. Bioclimatic variables from precipitation and temperature records vs. remote sensingbased bioclimatic variables: Which side can perform better in species distribution modeling? Ecol. Inform. 2020, 57, 101060. [CrossRef]

44. McGuffie, K.; Henderson-Sellers, A. The Climate Modelling Primer; John Wiley \& Sons: Hoboken, NJ, USA, 2014.

45. Lee, I.H.; Park, S.H.; Kang, H.S.; Cho, C.H. Regional climate projections using the HadGEM3-RA. In Proceedings of the 3rd International Conference on Earth System Modelling, Hamburg, Germany, 17-21 September 2012.

46. NIMS. National Institute of Meterological Sciences HadGEM3-RA. Available online: http://cordex-ea.climate.go.kr/cordex/ models.do (accessed on 19 July 2021).

47. Robert, J.; Hijmans, S.P.; Leathwick, J.; Elith, J. Species Distribution Modeling Package ‘Dismo'. 2020. Available online: https:/ / cran.r-project.org/web/packages/dismo/dismo.pdf (accessed on 11 October 2021).

48. Adhikari, P.; Shin, M.-S.; Jeon, J.-Y.; Kim, H.W.; Hong, S.; Seo, C. Potential impact of climate change on the species richness of subalpine plant species in the mountain national parks of South Korea. J. Ecol. Environ. 2018, 42, 36. [CrossRef]

49. Adhikari, P.; Jeon, J.-Y.; Kim, H.W.; Shin, M.-S.; Adhikari, P.; Seo, C. Potential impact of climate change on plant invasion in the Republic of Korea. J. Ecol. Environ. 2019, 43, 36. [CrossRef]

50. Shin, M.-S.; Seo, C.; Lee, M.; Kim, J.-Y.; Jeon, J.-Y.; Adhikari, P.; Hong, S.-B. Prediction of Potential Species Richness of Plants Adaptable to Climate Change in the Korean Peninsula. J. Environ. Impact Assess. 2018, 27, 562-581. [CrossRef]

51. Kim, H.W.; Adhikari, P.; Chang, M.H.; Seo, C. Potential Distribution of Amphibians with Different Habitat Characteristics in Response to Climate Change in South Korea. Animals 2021, 11, 2185. [CrossRef]

52. Adhikari, P.; Jeon, J.-Y.; Kim, H.W.; Oh, H.-S.; Adhikari, P.; Seo, C. Northward Range Expansion of Southern Butterflies According to Climate Change in South Korea. J. Clim. Chang. Res. 2020, 11, 643-656. [CrossRef]

53. Jeon, J.-Y.; Adhikari, P.; Seo, C. Impact of climate change on potential dispersal of Paeonia obovata (paeoniaceae), a critically endangered medicinal plant of South Korea. Ecol. Environ. Conserv. 2020, 26, S145-S155.

54. McDougall, K.L.; Lembrechts, J.; Rew, L.J.; Haider, S.; Cavieres, L.A.; Kueffer, C.; Milbau, A.; Naylor, B.J.; Nuñez, M.A.; Pauchard, A. Running off the road: Roadside non-native plants invading mountain vegetation. Biol. Invasions 2018, 20, 3461-3473. [CrossRef] 
55. Hong, S.H.; Lee, Y.H.; Lee, G.; Lee, D.-H.; Adhikari, P. Predicting Impacts of Climate Change on Northward Range Expansion of Invasive Weeds in South Korea. Plants 2021, 10, 1604. [CrossRef]

56. Elith, J.; Leathwick, J.R. Species distribution models: Ecological explanation and prediction across space and time. Annu. Rev. Ecol. Evol. Syst. 2009, 40, 677-697. [CrossRef]

57. Wiens, J.A.; Stralberg, D.; Jongsomjit, D.; Howell, C.A.; Snyder, M.A. Niches, models, and climate change: Assessing the assumptions and uncertainties. Proc. Natl. Acad. Sci. USA 2009, 106, 19729-19736. [CrossRef]

58. Shrestha, U.B.; Shrestha, B.B. Climate change amplifies plant invasion hotspots in Nepal. Divers. Distrib. 2019, 25, 1599-1612. [CrossRef]

59. Fournier, A.; Penone, C.; Pennino, M.G.; Courchamp, F. Predicting future invaders and future invasions. Proc. Natl. Acad. Sci. USA 2019, 116, 7905-7910. [CrossRef]

60. Elith, J.; Graham, C.H.; Anderson, R.P.; Dudik, M.; Ferrier, S.; Guisan, A.; Hijmans, R.J.; Huettmann, F.; Leathwick, J.R.; Lehmann, A. Novel methods improve prediction of species' distributions from occurrence data. Ecography 2006, 29, 129-151. [CrossRef]

61. Thuiller, W.G.D.; Gueguen, M.; Engler, R.; Breiner, F. Package 'biomod2': Ensemble Platform for Species Distribution Modeling, Version 3.5.1. 2021. Available online: https://cran.r-project.org/web/packages/biomod2/index.html (accessed on 11 October 2021).

62. Barbet-Massin, M.; Jiguet, F.; Albert, C.H.; Thuiller, W. Selecting pseudo-absences for species distribution models: How, where and how many? Methods Ecol. Evol. 2012, 3, 327-338. [CrossRef]

63. Pearson, R.G. Species' distribution modeling for conservation educators and practitioners. Lessons Conserv. 2010, 3, 54-89.

64. Allouche, O.; Tsoar, A.; Kadmon, R. Assessing the accuracy of species distribution models: Prevalence, kappa and the true skill statistic (TSS). J. Appl. Ecol. 2006, 43, 1223-1232. [CrossRef]

65. Thuiller, W.; Lavorel, S.; Araújo, M.B. Niche properties and geographical extent as predictors of species sensitivity to climate change. Glob. Ecol. Biogeogr. 2005, 14, 347-357. [CrossRef]

66. Lobo, J.M.; Jiménez-Valverde, A.; Real, R. AUC: A misleading measure of the performance of predictive distribution models. Glob. Ecol. Biogeogr. 2008, 17, 145-151. [CrossRef]

67. Swets, J.A. Measuring the accuracy of diagnostic systems. Science 1988, 240, 1285-1293. [CrossRef]

68. Farzin Shabani, L.K.; Ahmadi, M. Assessing accuracy methods of species distribution models: AUC, specificity, sensitivity and the true skill statistic. Glob. J. Hum. Soc. Sci. Res. 2018, 18, 7-17.

69. Dyderski, M.K.; Paź, S.; Frelich, L.E.; Jagodziński, A.M. How much does climate change threaten European forest tree species distributions? Glob. Chang. Biol. 2018, 24, 1150-1163. [CrossRef]

70. Phillips, S.J. A Brief Tutorial on Maxent 2017. Available online: https://biodiversityinformatics.amnh.org/open_source/maxent/ Maxent (accessed on 11 October 2021).

71. Baldwin, R.A. Use of maximum entropy modeling in wildlife research. Entropy 2009, 11, 854-866. [CrossRef]

72. Hulme, P.E.; Bacher, S.; Kenis, M.; Klotz, S.; Kühn, I.; Minchin, D.; Nentwig, W.; Olenin, S.; Panov, V.; Pergl, J. Grasping at the routes of biological invasions: A framework for integrating pathways into policy. J. Appl. Ecol. 2008, 45, 403-414. [CrossRef]

73. Adhikari, P.; Park, S.-M.; Kim, T.-W.; Lee, J.-W.; Kim, G.-R.; Han, S.-H.; Oh, H.-S. Seasonal and altitudinal variation in roe deer (Capreolus pygargus tianschanicus) diet on Jeju Island, South Korea. J. Asia-Pac. Biodivers. 2016, 9, 422-428. [CrossRef]

74. Phillips, S.J.; Elith, J. On estimating probability of presence from use-availability or presence-background data. Ecology 2013, 94, 1409-1419. [CrossRef] [PubMed]

75. Jarnevich, C.S.; Stohlgren, T.J.; Barnett, D.; Kartesz, J. Filling in the gaps: Modelling native species richness and invasions using spatially incomplete data. Divers. Distrib. 2006, 12, 511-520. [CrossRef]

76. West, A.M.; Kumar, S.; Brown, C.S.; Stohlgren, T.J.; Bromberg, J. Field validation of an invasive species Maxent model. Ecol. Inform. 2016, 36, 126-134. [CrossRef]

77. Li, X.; Wang, Y. Applying various algorithms for species distribution modelling. Integr. Zool. 2013, 8, 124-135. [CrossRef]

78. Breiman, L. Random forests. Mach. Learn. 2001, 45, 5-32. [CrossRef]

79. Stockwell, D. The GARP modelling system: Problems and solutions to automated spatial prediction. Int. J. Geogr. Inf. Sci. 1999, 13, 143-158. [CrossRef]

80. Hyung-Kyu, N.; Song, Y.-J.; Kwon, S.-I.; Eo, J.; Kim, M.-H. Potential changes in the distribution of seven agricultural indicator plant species in response to climate change at Agroecosystem in South Korea. Korean J. Ecol. Environ. 2018, 51, 221-233. [CrossRef]

81. Chung, M.Y.; Son, S.; Suh, G.U.; Herrando-Moraira, S.; Lee, C.H.; López-Pujol, J.; Chung, M.G. The Korean Baekdudaegan Mountains: A glacial refugium and a biodiversity hotspot that needs to be conserved. Front. Genet. 2018, 9, 489. [CrossRef]

82. Chung, G.Y.; Chang, K.S.; Chung, J.-M.; Choi, H.J.; Paik, W.-K.; Hyun, J.-O. A checklist of endemic plants on the Korean Peninsula. Korean J. Plant Taxon. 2017, 47, 264-288. [CrossRef]

83. Dullinger, I.; Wessely, J.; Bossdorf, O.; Dawson, W.; Essl, F.; Gattringer, A.; Klonner, G.; Kreft, H.; Kuttner, M.; Moser, D. Climate change will increase the naturalization risk from garden plants in Europe. Glob. Ecol. Biogeogr. 2017, 26, 43-53. [CrossRef]

84. Pellegrini, E.; Buccheri, M.; Martini, F.; Boscutti, F. Agricultural land use curbs exotic invasion but sustains native plant diversity at intermediate levels. Sci. Rep. 2021, 11, 1-10. [CrossRef]

85. Mortensen, D.A.; Rauschert, E.S.; Nord, A.N.; Jones, B.P. Forest roads facilitate the spread of invasive plants. Invasive Plant Sci. Manag. 2009, 2, 191-199. [CrossRef]

86. KOSIS. Yearly road statistictics. Available online: http:/ / kosis.kr (accessed on 18 July 2021). 
87. Catriona, E. Rogers, J.P.M. Climate change and ecosystems of the Mid-Atlantic Region. Clim. Res. 2000, 14, 235-244.

88. Ni, M.; Deane, D.C.; Li, S.; Wu, Y.; Sui, X.; Xu, H.; Chu, C.; He, F.; Fang, S. Invasion success and impacts depend on different characteristics in non-native plants. Divers. Distrib. 2021. [CrossRef]

89. Leishman, M.R.; Haslehurst, T.; Ares, A.; Baruch, Z. Leaf trait relationships of native and invasive plants: Community-and global-scale comparisons. New Phytol. 2007, 176, 635-643. [CrossRef]

90. Carboni, M.; Münkemüller, T.; Lavergne, S.; Choler, P.; Borgy, B.; Violle, C.; Essl, F.; Roquet, C.; Munoz, F.; Consortium, D. What it takes to invade grassland ecosystems: Traits, introduction history and filtering processes. Ecol. Lett. 2016, 19, 219-229. [CrossRef]

91. Pyšek, P.; Richardson, D.M. Traits associated with invasiveness in alien plants: Where do we stand. In Biol. Invasions; Springer: Berlin/Heidelberg, Germany, 2008; pp. 97-125.

92. Buri, A.; Cianfrani, C.; Pinto-Figueroa, E.; Yashiro, E.; Spangenberg, J.E.; Adatte, T.; Verrecchia, E.; Guisan, A.; Pradervand, J.-N. Soil factors improve predictions of plant species distribution in a mountain environment. Prog. Phys. Geogr. 2017, 41, 703-722. [CrossRef]

93. Pyšek, P.; Richardson, D.M. Invasive species, environmental change and management, and health. Annu. Rev. Environ. Resour. 2010, 35, 25-55. [CrossRef] 